\title{
Optimal and Simulation of HAWT Blade S809
}

\author{
Prof. Yogesh mishra ${ }^{1}$, Dr. Pushpendra kumar sharma ${ }^{2}$, \\ Pavan kumar barasker ${ }^{3}$ \\ Department of Mechanical Engineering NRI Institute of Science and Technology, Bhopal, India.
}

\begin{abstract}
The object of this study to analysis of airfoil S809 blade with optimized condition and prepare $3 D$ modeling when using Blade Element-momentum theory and Computational Fluid Dynamic theory.

The Standard Airfoil Data using to optimized the blade parameter like twisting angle and chord length. The aerodynamic study and pressure contour study on blade with CFD and FEM analysis, but the systematic term of Euler's Equation, forces magnitude and direction and the velocity attack to the blade is to be a 4 degree of angle of attack.

A blade acts much like an airplane wing, when the wind flow through blade and the pressure generation factor work to lifting the the blade. The Pressure gradient in upper and lower surface of blade is different which is cause the aerodynamic structure of blade. The simulation of wind turbine with large eddy and the equation use like Reynold-Average, Navier-Stokes and Direct Numerical Simulation.
\end{abstract}

\section{Introduction}

Wind energy is a source of renewable power which comes from air current flowing across the earth's surface. Wind turbines harvest this kinetic energy and convert it into usable power which can provide electricity for home, farm, school or business applications on small (residential), medium (community), or large (utility) scales[1]. Wind energy is one of the fastest growing sources of new electricity generation in the world today. These growth trends can be linked to the multi-dimensional benefits associated with wind energy. The electricity produced from wind power is said to be "clean" because its generation produces no pollution or greenhouse gases. As both health and environmental concerns are on the rise, clean energy sources are a growing demand. Wind is a renewable energy resource, it is inexhaustible and requires no "fuel" besides the wind that blows across the earth. This infinite energy supply is a security that many users view as a stable investment in our energy economy as well as in our children's' future. Wind power is a cost-competitive source of electricity, largely due to technological advancements, as well as economies of scale as more of these machines are manufactured and put online around the world. As well as being affordable, wind power is a locally-produced source of electricity that enables communities to keep energy dollars in their economy. Job creation (manufacturing, service, construction, and operation) and tax base increase are other economic development benefits for communities utilizing wind energy. Generally there are two main type of wind turbine i.e. Horizontal axis wind turbine and vertical axis wind turbine, which is classified by the rotation of shaft. The rotation of shaft parallel to the ground is called as horizontal-axis wind turbine and the rotation of shaft is perpendicular to the ground is called as vertical-axis wind-turbine.

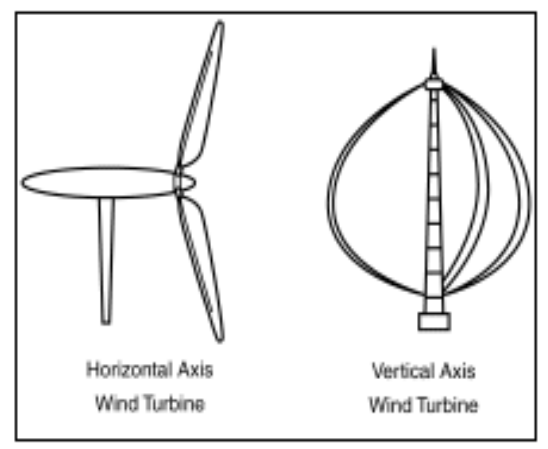

Figure 1 HAWT and VAWT

Horizontal axis wind turbine have a better efficiency as compare to the Vertical Axis wind turbine HAWT produce more electricity at wide range farm in any type of field at both low and high speed of wind. Maximum industries are working on this section to optimized and more efficient to wind turbine. Mainly the focus of optimization in wind turbine are tip speed ration, angle of attack, twisting angle and chord length etc. 


\section{Material And Design Parameters}

Carbon fiber 395 has some benefits which cause we selected:

- Low material density

- Excellent Stiffness

- Higher graphitization level

- Elevated temperature performance

- Good translation of fiber property

- Control matrix flow in process

- Electro-chemical oxidation effect

Design parameter for the preparation of 3D blade of wind turbines are taking standard for suitable verified to the blade element theory and bitz's law. Normal blade parameter of twisting angle and chord length are calculated in based of basic formulation of blade design and other parameter taken a constant [8]. As per standard, The blade is optimized by hit and try method to get more feasible design of twisting angle and chord length for the standard normal blade and optimized blade given below:

$\lambda=7.0, y=0.018, \alpha \_d=8.1, C l \_=0.9, B=3, R=21 \mathrm{~m}$

Tip- speed ratio=

7
0.018
0.9
3
21

glide ratio=

lift coefficint

Number of Blade

21

Length of blade

\begin{tabular}{|c|c|}
\hline \multicolumn{2}{|c|}{ Normal Blade } \\
\hline TwistingAngle & Chord length \\
\hline 28.572 & 3.0937 \\
\hline 24,443 & 3.0676 \\
\hline 20.969 & 2.9532 \\
\hline 15.592 & 2.6346 \\
\hline 11.73 & 2.317 \\
\hline 8.876 & 2.043 \\
\hline 6.702 & 1.8155 \\
\hline 5.003 & 1.6276 \\
\hline 3.642 & 1.4717 \\
\hline 2.53 & 1.341 \\
\hline 1607 & 1.2302 \\
\hline 0.828 & 1.1352 \\
\hline 0.164 & 1.0524 \\
\hline-0.037 & 1027 \\
\hline .0 .41 & 0.9788 \\
\hline$\cdot 0.911$ & 0.9109 \\
\hline .1 .35 & 0.84 \\
\hline-1.74 & 0.7699 \\
\hline .2 .087 & 0.6729 \\
\hline .2 .297 & 0.58 \\
\hline $.2,3988$ & 0.5153 \\
\hline
\end{tabular}

Optimized Blade
\begin{tabular}{|c|c|}
\hline Twisting Ang e & Chord length \\
\hline 17.4914 & 2.2511 \\
\hline 16.8186 & 2.1910 \\
\hline 16.1459 & 2.1308 \\
\hline 14.8004 & 2.0104 \\
\hline 13.4550 & 1.8901 \\
\hline 12.1095 & 1.7697 \\
\hline 10.7640 & 1.6493 \\
\hline 9.4186 & 1.5290 \\
\hline 8.0731 & 1.3761 \\
\hline 6.7276 & 1.2385 \\
\hline 5.3822 & 1.1146 \\
\hline 4.0367 & 1.0032 \\
\hline 2.6912 & 0.9028 \\
\hline 1.3457 & 0.7674 \\
\hline 0.0003 & 0.6523 \\
\hline 0.0000 & 0.5545 \\
\hline 0.0000 & 0.4713 \\
\hline 0.0000 & 0.3770 \\
\hline 0.0000 & 0.3016 \\
\hline 0.0000 & 0.2413 \\
\hline 0.00000 & 0.2413 \\
\hline
\end{tabular}

Analysis Of Optimized Blade

Using above parameter of airfoils S809 for Optimized Blade are kept in modeling software (Solidwork) and make 3D model of blade which is interact with the environment. The angle of attack of air is $4^{\circ}$ maintain in the environment. The Whole model is transfer to the ansys fluent software and meshing the geometry on it that is show in figure below. 


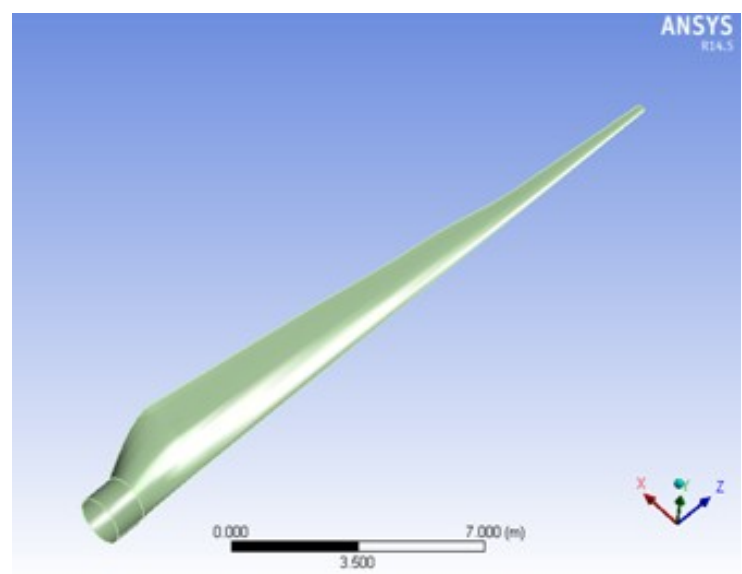

Figure 2 Optimized Blade Modeling in Ansys

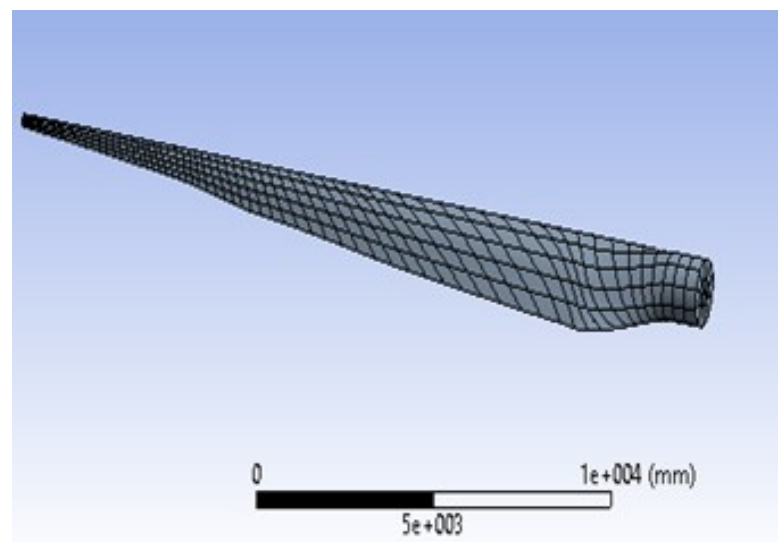

Figure 3 Meshing of Optimized Blade

The Environment domain type is air and fluid type is Air ideal Gas that all consider parameter in ansys Fluent workbanch, also we define inlet an outlet parameter in the geometry[5]. The Experimental velocity of air is $9 \mathrm{~m} / \mathrm{s}$ and pressure velocity scheme is consider as sample with spatial discretization gradient is least squares cell based and wind momentum is to be Second order upwind [2,3]. Define all boundary condition, after that initialized the solution from the inlet and start the calcultaion. After calculation we get the result the streamline flow of air and pressure conture show in figure.

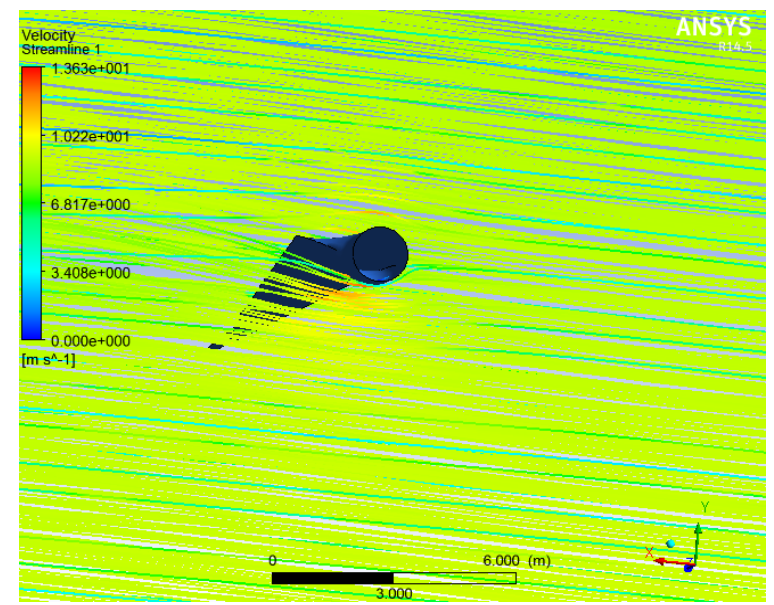

Figure 4 Velocity Streamline of Air 


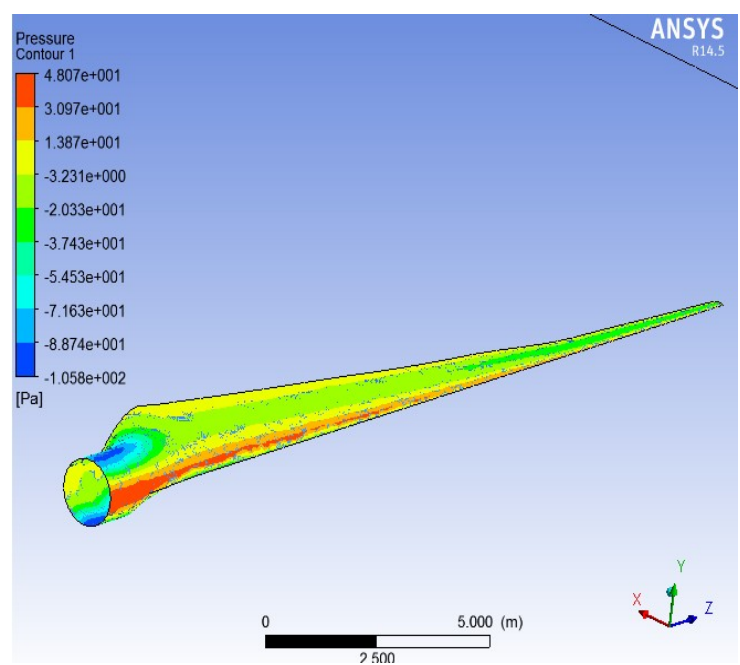

Figure 5 Pressure distributions in Blade

Pressure is produce the forces which is acting on a blade and that is maximum $122.82 \mathrm{~Pa}$ and this forces transfer in to static structure model as consider the cantilever beam.

\section{CFD Load Transfer Summary In new optimized Design}

Mechanical.

All values correspond to the CFD results before the application of any Scale or Offset operations set in

CFD Computed Forces from CFD Results File

$\mathrm{X}$-component $=136.26 \mathrm{~N}$

Y-component $=-626.07 \mathrm{~N}$

Z-component $=55.696 \mathrm{~N}$

Mechanical Mapped Forces for Mechanical Surface File

$\mathrm{X}$-component $=111.64 \mathrm{~N}$

Y-component $=-526.53 \mathrm{~N}$

Z-component $=53.176 \mathrm{~N}$

$100 \%$ of Mechanical nodes were mapped to the CFD surface show in figure 6 . Transfer loading condition to theblade, the stress, strain and deformation of blade are calculated show in table 3 and the effected contour respectively show in figure :

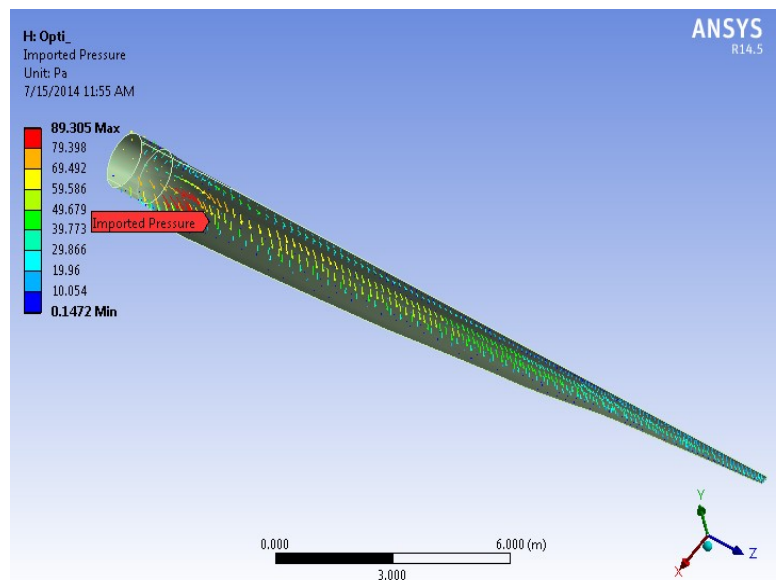

Figure 6 Pressure Deformations From Blade 


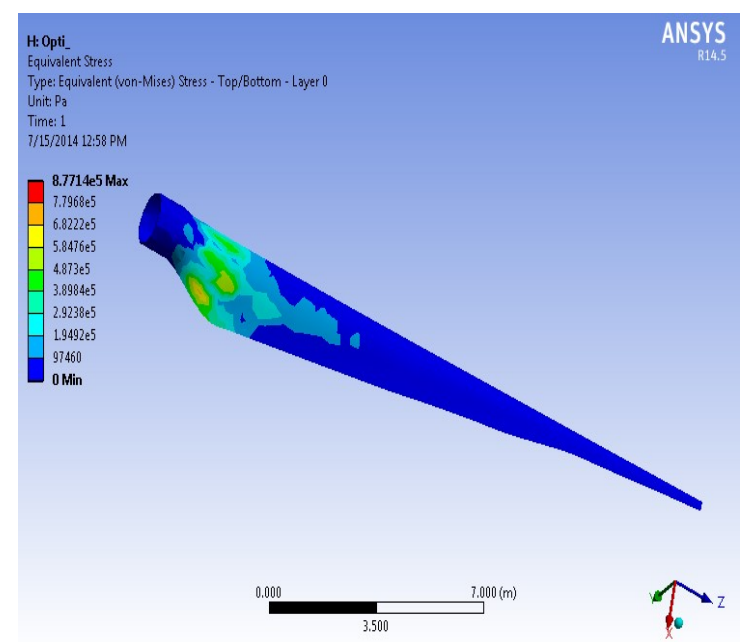

Figure 7 Stress Deformation Analysis

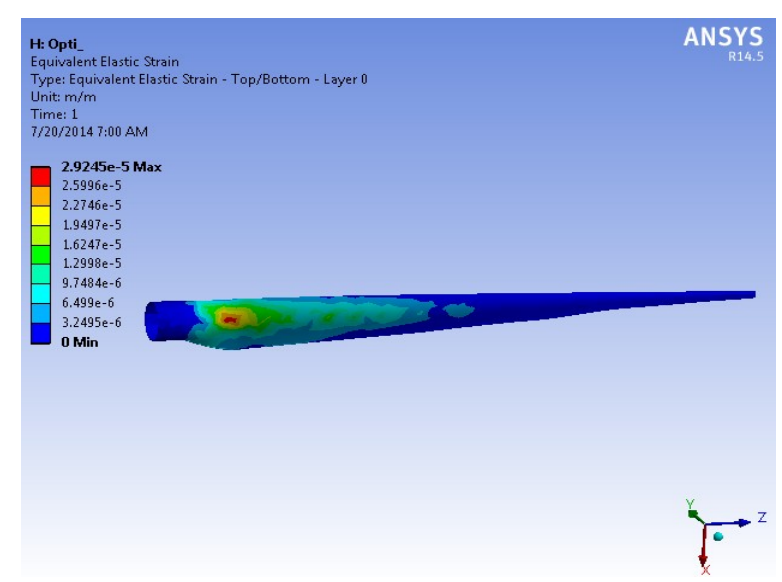

Figure 8 Strain Deformation Analysis

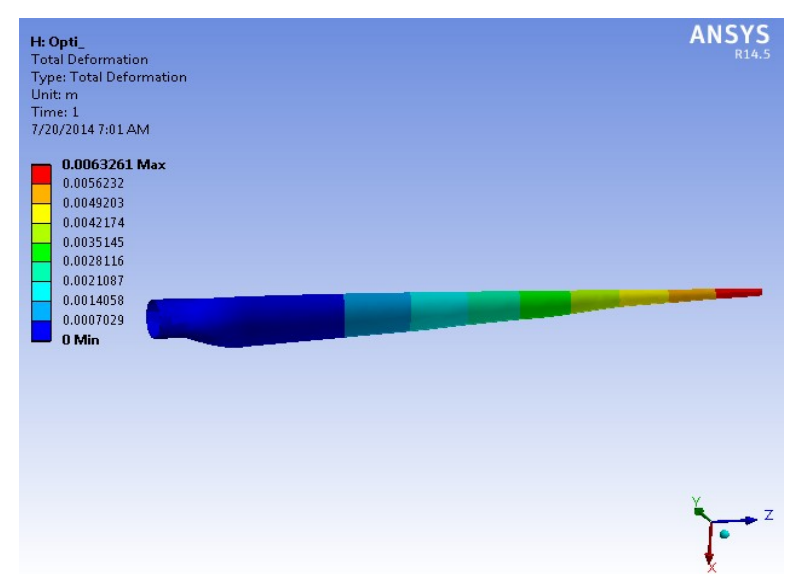

Figure 9 Total Deformation Analysis

Static structure analysis of blade, the maximum stress value is $8.7714 \mathrm{e}+05 \mathrm{~Pa}$ and elastic strain value is $2.9245 \mathrm{e}-05 \mathrm{~m} / \mathrm{m}$. The maximum total deformation of the blade is $6.3261 \mathrm{e}-03$ and maximum deflection occurs into the root of blade

\section{Conclusion}

In this paper, the horizontal axis wind turbine blade with airfoil S809 is design optimized at different parameter and analysis of wind flow. For CFD analysis of Optimized wind blade is done on ansys fluent software and the static structure module use for static analysis. Figure 4 shows the stream line distribution of wind into the blade and also more concentrating area. The wind velocity of angle of attack is $4^{\circ}$ at $9 \mathrm{~m} / \mathrm{s}$ and that 
developed pressure contour in the blade. The pressure is converted into the force parameter and study of static structure analysis of blade at considers a cantilever bean. The blade hub portion is fixed and the forces distribute over the blade at CFD load transfer to static structure module as show in figure 6. The Analysis of static structure, Stress, strain and deformation result got and that is show in figure 7-9.

\section{Reference}

[1]. Ravi Anant Kishore, Thibaud Coudron, Shashank Priya "Small-scale wind energy portable turbine (SWEPT)" United States , 2013.

[2]. Kim B, Kim J, Kikuyama K, Rooij V, Lee Y 3D numerical prediction of horizontal axis wind turbine power characteristics of the scales delft university T40/500 model, the fifth JSME-KSME fluids engineering conference, Japan.

[3]. Mandas N, Cambuli F, Carcangiu CE, Numerical prediction of horizontal axis wind turbine flow, European wind energy conference, Athens, Grecce.

[4]. Mr. Monir Chandrala, Prof. Abhishek Choubey and Prof. Bharat Gupta, 2012, Aerodynamic Analysis Of Horizontal Axis Wind Turbine Blade, International Journal of Engineering Research and Application, Vol. 2, Issue 6, Nov.-Dec. 2012 , pp. 1244-1248.

[5]. Ansys CFD tutorial.

[6]. Martin O.L., Hansen, Aerodynamics of Wind Turbines, Earth scan, 2008.

[7]. Kidwind Science Snack: Bitz Limit.

[8]. Manwell J. F., McGowan J. G., Rogers A. L., Wind Energy Explained: Theory, Design and Application, John Wiley \& Sons Ltd. ,2002. 